\title{
JUDICIALIZAÇÃO DA POLítICA EDUCACIONAL: UMA ANÁLISE DA ATUAÇÃO dO MINISTÉRIO PÚBLICO E DO TRIBUNAL DE JUSTIÇA dO PARANÁ
}

\begin{tabular}{c} 
EDUCATION POLICY LITIGATION: \\
AN ANALYSIS OF THE PERFORMANCE OF THE PUBLIC \\
PROSECUTION OFFICE AND THE COURT OF JUSTICE OF PARANÁ \\
\hline JUDICIALIZACIÓNDE LA POLÍTICA EDUCACIONAL: \\
UN ANÁLISIS DE LA ACTUACIÓN DEL MINISTERIO \\
PÚBLICO Y DEL TRIBUNAL DE JUSTICIA DE PARANÁ
\end{tabular}

Adriana Dragone Silveira ${ }^{1}$

RESUMO: O artigo tem por objetivo analisar a atuação do Ministério Público (MP) e Poder Judiciário com relação à educação no estado do Paraná, buscando compreender as possibilidades e os limites do processo de judicialização para a expansão do direito à educação. A judicialização da educação neste trabalho é compreendida como deslocamento da discussão dos conflitos educacionais das arenas tradicionais, legislativo e executivo, para as instituições do Sistema de Justiça. No âmbito do Paraná, os conflitos educacionais julgados pelo Tribunal de Justiça foram analisados em 514 decisões, no período de 1995 a 2014. Os resultados indicam que a maioria das ações é ingressada visando uma demanda individual, buscando a solução de um conflito para cada indivíduo e/ou para um grupo determinado, tendo-se um percentual pequeno de ações coletivas. Destaca-se o número expressivo de ações questionando o ingresso no primeiro ano do ensino fundamental. Sobre esse tema o Judiciário e o MP foram decisivos para a alteração da política educacional no estado, em oposição ao Conselho Estadual de Educação. Outro tema de destaque refere-se às demandas objetivando a matrícula na educação infantil como produto do planejamento estratégico do MP.

PAlaVRAS-ChaVE: Direito à educação. Política educacional. Judicialização da educação. Ministério Público.

ABSTRACT: This article aims at analyzing the performance of the Public Prosecution Office (PPO) and the Judiciary regarding the education in the state of Paraná, attempting to understand possibilities and limitations of litigations aimed at expanding the right to education. In this research, the process of education litigation is understood as the displacement of discussions regarding educational conflicts from the traditional spheres of Executive and Legislative branches toward the Justice System institutions. In the state of Paraná,514 judicial decisions related to educational conflicts were located between the years of 1995 and 2014. The results show that most lawsuits were individual, demanding solutions for the conflicts of specific individuals or small groups, with a small percentage of collective actions. The number of lawsuits requiring admission to the first grade of Elementary School stands out. In this specific matter, the Judiciary and the PPO were crucial for a shift in the state education policy by opposing the decision made by the State Education Council. It is also possible to highlight the issue of providing early childhood education, which stood out in consequence of a strategic planning of the PPO.

KEYWORDS: Right to education. Education policy. Education litigation. Public Prosecution Office.

Submetido em: 22/08/2017 - Aceito em: 07/02/2018 - Publicado em: 08/02/2018.

\begin{tabular}{l|c|c|c|c|c|c|} 
(C) Rev. Educ. Perspec. & Viçosa, $M G$ & v.8 & n.3 & AOP & set./dez. 2017 & eISSN 2178-8359 \\
\hline
\end{tabular}


RESUMÉN: Este articulo objetiva analizar la actuación del Ministerio Público (MP) y del Poder Judicial con relación a la educación en el estado de Paraná, en la búsqueda de comprender las posibilidades y limitaciones de la judicialización para la expansión del derecho a educación. Se entiende la judicialización de la educación en este trabajo como el desplazamiento de discusiones acerca de conflictos educacionales desde las esferas tradicionales del Legislativo y del Executivo hacia las instituciones del Sistema de Justicia. En el ámbito de Paraná, los conflictos juzgados por el Tribunal de Justicia fueron analizados a partir de 514 decisiones ubicadas en el periodo entre 1995 y 2014. Los resultados indican que la mayoría de las acciones se ingresan por la vía individual, buscando solución de conflictos para individuos y pequeños grupos determinados, habiendo un pequeño porcentaje de acciones colectivas. Se destaca el numero expresivo de acciones cuestionando el ingreso en el primer año de la enseñanza fundamental. En este tema, la actuación del Judiciario y del MP fueron cruciales para un cambio en la política educacional del estado, por su oposición al Consejo Estadual de Educación. Otro tema bastante representado fueron las demandas para ampliación de oferta en la educación infantil, en consecuencia del planeamiento estratégico del MP.

PAlabras Clave: Derecho a educación. Política educacional. Judicialización de la educación. Ministerio Público.

\section{INTRODUÇÃO}

No Brasil, a Constituição Federal de 1988 (CF/88) foi responsável pela ampliação de direitos civis, políticos, econômicos, sociais, culturais, assim como por ampliar e aperfeiçoar os intrumentos legais (ação civil pública, mandado de segurança, mandado de injunção) e as instituições (Ministério Público e Defensoria Pública) para que os cidadãos possam utilizar-se a fim de questionar a reivindicação de seus direitos junto aos Tribunais (SOUSA SANTOS, 2007). Com a CF/88, a defesa dos direitos de cidadania passa a não depender de ações individuais de cada cidadão lesado, permitindo ao Ministério Público (MP) o controle dos atos administrativos na garantia dos direitos constitucionais.

Contudo, se faz necessário destacar que a transformação de um conflito em um litígio constituiu-se em uma alternativa entre outras, segundo Santos et. al. (2007), podendo variar de país para país e entre grupo social e área de interação. Dessa forma, cabe destacar que baixos índices de litigiosidade não implicam em baixa incidência de ações lesivas, pois fatores que ocasionam o conflito podem não ser percebidos pelos grupos lesados, e/ou não saberem da possibilidade de acessar as estruturas do Poder Judiciário para exigir a sua concretização (SOUSA SANTOS et. al., 1996).

A judicialização da política tem sido compreendida como deslocamento da discussão dos conflitos educacionais das arenas tradicionais, legislativo e executivo, para o judiciário (RIOS-FIGUEROA; TAYLOR, 2006; BARROSO, 2009), todavia, neste trabalho, desenvolver-se-à a discussão de que este fenômeno na educação não se restringe à intervenção nos Tribunais de Justiça, mas também de outras instituições que compõem o sistema de Justiça como o MP, na sua atuação extrajudicial. 
Este fenômeno da judicialização da política e também das políticas públicas específicas, como saúde e educação, vem crescendo nos últimos anos. De acordo com Tate e Vallinder (1995), algumas condições facilitam a judicialização da política, como: a democracia; a separação de poderes; o reconhecimento formal de direitos; a consciência dos meios judiciais pelos grupos de interesses e pelos partidos de oposição na realização de seus objetivos; inefetividade das instituições majoritárias; a incapacidade das instituições em dar provimento às demandas sociais, delegando às cortes a tomada de decisão em determinadas áreas da política.

Taylor (2007) evidencia que nas últimas duas décadas o Judiciário tem se revelado um importante ator político, relevante para o debate das políticas públicas. Destaca-se que as demais instituições integrantes deste Sistema de Justiça, em seus distintos tribunais, e institições como MP, Defensoria Pública, Advocacia - principalmente pela Ordem dos Advogados do Brasil (OAB), têm atuado nas diversas fases do processo de política pública ${ }^{1}$. No âmbito da educação, uma das instituições responsáveis pelo crescimento da exigibilidade da educação no Judiciário nos últimos anos é o MP, decorrente das suas funções constitucionais e também das estabelecidas pelo Estatuto da Criança e do Adolescente (ECA/1990) (MARTINES JR, 2006; SILVEIRA, 2010).

Entretanto, a intervenção dos Tribunais nos processos sobre alocação de recursos, realização de programas sociais, definição de prioridades de ação governamental não é consenso, pelo caráter democrático dessa interferência, considerando a independência dos poderes do Estado, questionando a apreciação pelo Judiciário de questões da esfera da Administração Pública (DUARTE, 2006; 2007).

No Brasil, estudos acerca do papel das instituições de justiça e o conteúdo produzido (ações e decisões) sobre o direito à educação, têm início em 1995, com a tese de Oliveira, na qual o autor apresenta os mecanismos que possibilitam tornar a educação um direito efetivo: sua declaração, mecanismos de exigibilidade e a intervenção do Sistema de Justiça. A partir dessa pesquisa, outras se seguiram com o intuito de sistematizar e analisar o conteúdo das decisões judiciais e a atuação do poder judiciário frente às demandas do direito à educação, sejam na instâncias superiores, Supremo Tribunal Federal e Superior Tribunal de Justiça, como os trabalhos de Machado (2003), Scaff e Pinto (2016) ou nos Tribunais Estaduais, em São Paulo, Marinho (2009) e Silveira (2012); Minas Gerais, Cury e Amaral (2014), Rio Grande do Sul por Gottlieb (2011).

Os temas discutidos no âmbito do Judiciário são os mais variados: acesso a todas as etapas e modalidades da educação básica, financiamento da educação, eleição de diretores, qualidade, retenção de documento por falta de pagamento de anuidades, corte etário para matrícula, implementação de componentes curriculares, evasão escolar, transporte. Esses trabalhos

\begin{tabular}{|l|c|c|c|c|c|c|} 
(C) Rev. Educ. Perspec. & Viçosa, $M G$ & v.8 & n.3 & AOP & set./dez. 2017 & eISSN 2178-8359 \\
\hline
\end{tabular}


analisam as decisões judiciais, buscando compreender como os Tribunais analisam, julgam e intervém para proteger aspectos relacionados ao direito à educação.

A maneira como a atuação do MP vem sendo realizada também pode revelar indícios que ajudam na compreensão do fenômeno da judicialização da educação. Destaca-se também crescimento das pesquisas sobre a atuação do MP para a garantia do direito à educação, tanto por pesquisadores da área do direito quanto da educação. A maioria das produções são dissertações nas quais os autores analisam medidas judiciais e/ou extrajudiciais realizadas pelas promotorias de justiça que atendem a área da educação. Dentre as produções, destaca-se o trabalho de Silveira (2006) sobre Promotorias de Justiça de dois municípios paulistas, Damasco (2008) sobre as Recomendações instauradas junto às promotorias de justiça do Distrito Federal e Territórios; Braga (2011) que realiza levantamento das ações para garantia da educação do município de Belém do Pará e analisa o papel do MP como fiscalizador e Borges (2007) que realiza um estudo sobre a atuação dos sistemas de justiça na efetivação do direito à educação básica na comarca de Florianópolis, em Santa Catarina. A partir desses estudos, fica evidente a importância do papel do MP para a garantia do direito à educação. A atuação das promotorias de justiça que defendem a área da educação podem trazer mudanças significativas quando as medidas judiciais ou extrajudiciais geram uma efetividade na formulação e aplicação de políticas públicas, de maneira que pode colaborar com a garantia do direito, contudo, os autores destacam que é imprescindível a participação da sociedade civil neste processo.

Além do MP, a exigibilidade do direito à educação tem sido realizada também por outros atores do Sistema de Justiça, como a Defensoria Pública (CAJUELLA, 20016), Ordem dos Advogados do Brasil, instituições que podem atuar na garantia do direito e na discussão da política em suas diversas fases, as quais ainda são pouco exploradas em pesquisas específicas.

Desta forma, este artigo tem por objetivo averiguar e analisar a atuação do MP e do Poder Judiciário com relação à educação no Estado do Paraná (PR), buscando compreender as possibilidades e os limites do processo de judicialização para a expansão do direito à educação. Para tanto, analisar-se-á a intervenção do MP no estado a partir das atividades do Centro Operacional às Promotorias de Justiça da Criança e do Adolescente e Educação (CAOPCAE) - Área de Educação, por meio de entrevista com a Coordenadora e documentos institucionais, e da análise das decisões envolvendo educação julgadas pelo Tribunal de Justiça do PR. 


\section{DAS AÇÕES DESENVOLVIDAS PELO MP DO PR: ANÁLISE DA ATUAÇÃOO DO CENTRO OPERACIONAL ÀS PROMOTORIAS DE JUSTIÇA DA CRIANÇA E DO ADOLESCENTE E EDUCAÇÃO (CAOPCAE) - ÁREA DE EDUCAÇÃO}

O Centro de Apoio Operacional às Promotorias de Justiça de Proteção à Educação do PR foi criado pelo Ato $\mathrm{n}^{\mathrm{o}}$ 27, de 9 de abril de 2002. O MP do PR foi um dos primeiros estados brasileiros a ter um Centro de Apoio relacionado à educação. As matérias de atuação estão relacionadas às seguintes questões:
a) de proteção dos direitos relacionados à educação;
b) de acesso à educação;
c) de combate à evasão escolar;
d) de verificação da destinação dos percentuais dos recursos públicos constitucionalmente previstos à área de educação;
e) de fiscalização da aplicação das verbas públicas na educação, inclusive oriundas do FUNDEF (PARANÁ, MINISTÉRIO PÚBLICO, Ato 27/2002, Parágrafo único, art. $6^{\circ}$ ).

As atribuições previstas pelas alíneas "d" e "e" foram reconhecidas como atribuições das Promotorias de Proteção ao Patrimônio Público. Em 2012, o então procurador geral do MP do PR anexou o Centro de Apoio à Educação ao Centro de Apoio da Criança e Adolescente, sob a denominação de Centro de Apoio Operacional às Promotorias de Justiça da Criança e do Adolescente e da Educação (CAOPCAE), preservando as atribuições do Ato 27/2002. Todavia, cabe destacar que em novembro de 2013, o Colégio Nacional dos Procuradores Gerais $(\mathrm{CNPG})^{2}$ fez uma recomendação para a criação de Centro de Apoio específico da educação e Promotorias específicas da educação, com o estabelecimento de atribuições, incluindo o acompanhamento das verbas. Também em junho de 2013, o Conselho Nacional dos Procuradores-Gerais do MP dos Estados e da União aprovou uma recomendação nacional a todos os Órgãos do MP brasileiro para que instituíssem Promotorias Especializadas de Educação e Centros de Apoio Operacional Especializados em Educação, além de estabelecer outras matérias de atuação às Promotorias de Justiça de Proteção à Educação, estendendo a competência na área da educação ${ }^{3}$, incluindo o acompanhamento das verbas.

Desde a criação do Centro de Apoio à Educação, uma Promotora de Justiça foi designada para a realização de suas atividades, afastando-se por um período de quase dois anos, mas retomando as funções em 2008. O que demonstra uma estabilidade do exercício das atividades do Centro de Apoio vinculadas ao único Promotor de Justiça. Em conjunto ao Centro de Apoio funciona também a Promotoria de Proteção à Educação de Curitiba, sendo a mesma Promotora de Justiça a responsável pela execução das atividades. Segundo o Plano Setorial de Ação da Promotoria de Justiça de Proteção à Educação constam as seguintes

\begin{tabular}{l|c|c|c|c|c|c} 
(C) Rev. Educ. Perspec. & Viçosa, $M G$ & v.8 & n.3 & AOP & set./dez. 2017 & eISSN 2178-8359 \\
\hline
\end{tabular}


ações: acompanhamento da proibição do corte etário, auxiliar no combate a evasão escolar, acompanhar a demanda recepcionada por falta de vagas em ensino fundamental e médio, inquérito civil para a falta de vagas em educação infantil (EI) e acompanhar a oferta de educação especial em inclusão.

A estrutura do CAOPCAE - Educação e da Promotoria de Proteção à Educação de Curitiba conta, como já destacado, com apenas uma Promotora de Justiça, uma assessora jurídica, duas estagiárias de graduação de Direito, uma de pós-graduação e dois estagiários de ensino médio. E a Promotoria de Educação tem duas assessoras. A estrutura mostra-se insuficiente, considerando as demandas e a atuação desenvolvida pelos profissionais. O Centro de Apoio possui uma página eletrônica na internet ${ }^{4}$, todavia não é atualizada com frequência, pois não possui um técnico para o suporte.

A comunicação do Centro de Apoio com os Promotores de Justiça tem sido feita por meio de informativos virtuais semanais, com o objetivo de "manter os Promotores de justiça atualizados sobre os temas de natureza jurídica e afins da área da educação" (Promotora de Justiça do CAOPCAE - Área Educação). Os assuntos dos informativos são escolhidos devido à procura pelos promotores ou por dizerem respeito a informações de abrangência nacional, sobre a educação, e sempre são concisos.

A EI é o principal tema de ação do Centro de Apoio e incorporada ao Planejamento Estratégico do MP de 2011. O Projeto Estratégico do MP para a concretização do direito à educação intitulado "Atuação do MP do Estado do PR para a criação de vagas em educação infantil" foi lançado por meio da "Campanha 100\% pré-escola e creche para todos" em 2011. Nesse projeto, o Centro de Apoio orientou os Promotores de Justiça com um roteiro de atuação, contendo um rol de materiais com sugestões de como fazer esse acompanhamento, com modelos de atuação (Inquérito Civil, Ação Civil Pública, Termo de Ajustamento de Conduta (TAC) e levantamento estatístico sobre a situação da EI nos municípios paranaenses. A taxa de atendimento na pré-escola no estado em 2010 era de 77,7\% e no Brasil 81,4\% e na creche $30,3 \%$ no PR e $23,2 \%$ no Brasil ${ }^{5}$.

As demandas por ensino fundamental (EF), desconsiderando as que se referem à data de corte etário para ingresso no primeiro ano, estão relacionadas à escolha de escolas, sendo a procura por falta de vaga mais difícil. Segundo a Promotora de Justiça, isso ocorre porque os municípios têm incorporado mais a obrigação com esta etapa obrigatória, procurando evitar a falta de vagas. Sobre a atuação do MP no que se refere à regulamentação de uma data corte para ingresso no EF, esta instituição promoveu uma Ação Civil Pública, em 2006, com julgamento favorável em liminar. A ação tinha dois objetos, o primeiro remetia ao prazo para a instituição do EF de nove anos, pois o Conselho Estadual de Educação (CEE) do PR 
deliberou um prazo menor. $\mathrm{O}$ segundo objeto consistia no pedido de revogação de um artigo da deliberação do CEE, estabelecendo a data para o corte etário.

O Centro de Apoio, quanto a esse tema, seguiu orientando os Promotores de Justiça para o cumprimento da liminar, pois segundo a Promotora de Justiça haviam muitos municípios que não cumpriam, "ignorando" a decisão judicial". Destaca-se, também, a elaboração pelo CAOPCAE - Área Educação da Nota Técnica 01/2008, com a seguinte sugestão de atuação pelos órgãos ministeriais:

[...] o Centro de Apoio Operacional às Promotorias de Justiça de Proteção à Educação encaminha aos membros do MP do Estado do PR dossiê contendo material legislativo (inclusive projetos de lei estadual e federal), processual/judicial (inicial da ACP, manifestações processuais, liminares, sentença de mérito, acórdãos em pedidos de suspensão de liminares, agravos regimentais, acórdãos em agravos regimentais, parecer da Procuradoria-Geral da República em ADC, dentre outros) e normativo (aqui incluídos os atos emanados dos conselhos de educação - estadual e federal), bem como sugestão de recomendação administrativa, minutada por este Centro de Apoio, a ser encaminhada, conforme análise da conveniência e oportunidade levada a efeito pelo agente ministerial, ao órgão municipal, com o propósito de ver assegurada a ordem jurídica e preservado o direito à educação, em sua acepção constitucional - justa e igualitária, portanto, àquela parcela da população que completará seis anos de idade - independentemente do dia de seu aniversário - para que efetive sua matrícula no primeiro ano do ensino fundamental de nove anos de duração [...]. (PARANÁ, MINISTÉRIO PÚBLICO, 2008, p. 1516).

O CAOPCAE - Área Educação mostrou-se fundamental para o desenvolvimento do trabalho do MP na área da educação no estado, dado este coletado nas entrevistas com os Promotores de Justiça nas diversas Comarcas, fornecendo materiais e possibilitando a troca de informações sobre um tema com diversas especificidades, por meio de informativos e página da internet. Assim como, os Promotores recorrem com frequência aos profissionais do Centro de Apoio para tirar dúvidas, trocar informações e buscar materiais, como recomendação administrativa, modelos de TAC e Ação Civil Pública.

Para a plena realização do trabalho destaca-se a especialização na área educacional pela Promotora de Justiça coordenadora e sua estabilidade na função. Entretanto, ressalta-se que a união do Centro de Apoio da Educação ao Centro de Apoio da Infância e Juventude, ainda que formalmente, sem mudanças na estrutura de trabalho, pode ser um fator de secundarização da área, principalmente em um momento nacional que o MP reconhece a importância de especializar a área da educação, com a criação de comissões específicas na área da educação nacionalmente.

A inclusão de uma meta educacional no planejamento estratégico institucional também é um importante resultado do esforço do CAOPCAE - Área Educação. A previsão da ampliação das vagas em EI, nesse plano, em conjunto com as inúmeras demandas da população, fez com

\begin{tabular}{l|c|c|c|c|c|c|} 
(C) Rev. Educ. Perspec. & Viçosa, $M G$ & v.8 & n.3 & AOP & set./dez. 2017 & eISSN 2178-8359 \\
\hline
\end{tabular}


que, em muitas comarcas, esse fosse o tema principal de atuação do MP. A definição de uma área estratégica para o foco de atuação, tanto do CAOPCAE quanto da Promotoria, se torna fundamental para um trabalho mais efetivo da instituição.

\section{MAPEAMENTO DAS DECISÕES DO PODER JUDICIÁRIO DO ESTADO DO PR COM RELAÇÃO AO DIREITO À EDUCAÇÃO}

Para averiguar e analisar a atuação do Poder Judiciário com relação à educação no Estado do PR, buscou-se caracterizar e analisar as demandas educacionais apreciadas pelo Tribunal de Justiça do estado do PR (TJ-PR), instância intermediária no Sistema de Justiça. Cabe destacar que todas as ações envolvendo o poder público, julgadas em primeira instância pelos juízes singulares, precisam ser apreciadas em recurso por um Tribunal de Justiça estadual. Assim, ao analisar os julgados de um Tribunal estadual é possível ter um conjunto significativo ${ }^{6}$ de decisões judiciais envolvendo os conflitos educacionais do tal estado. Para a coleta de dados, recorreu às decisões judiciais do $\mathrm{TJ}-\mathrm{PR}^{7}$. As decisões versando sobre a educação básica julgadas no período de $1995-2014$ totalizam $514^{8}$ para o estudo desta pesquisa. No estudo realizou-se uma análise descritiva das decisões do Tribunal de Justiça do PR a partir da distribuição das ações ao longo dos anos, temáticas das ações, recurso jurídico utilizado e partes envolvidas, por meio da organização de um banco de dados e cruzamento em infográficos.

A maioria das decisões versando sobre educação no TJ-PR discutiu questões envolvendo o EF (55,5\%), seguida das demandas em EI 26,8\%, conforme infográfico 1:

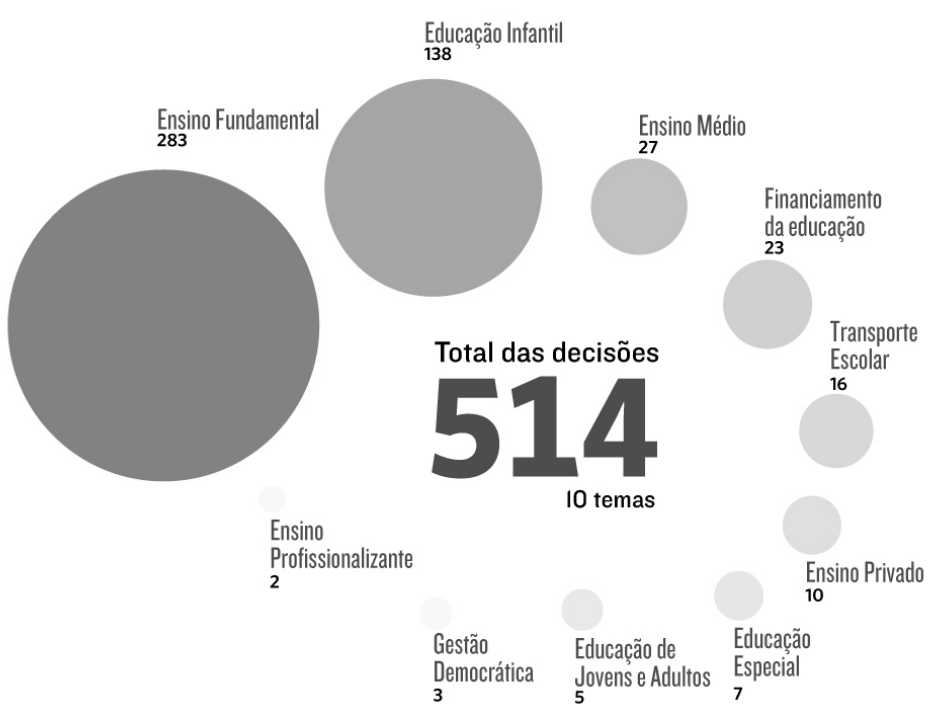

Infográfico1. Decisões do TJ-PR versando sobre educação, organizadas por temas (1995-2014)

Fonte: Banco de dados de decisões organizado para esta pesquisa

\begin{tabular}{l|c|c|c|c|c|c|} 
(C) Rev. Educ. Perspec. & Viçosa, $M G$ & v.8 & n.3 & AOP & set./dez. 2017 & eISSN 2178-8359 \\
\hline
\end{tabular}


Observando o número de decisões por ano (infográfico 2 e 3), nota-se que há um crescimento a partir de 2008, com 63 decisões e 72 no ano de 2009 e uma maior incidência em 2014, com 150 casos analisados. Entretanto, cabe destacar que não há uma constância nesses julgamentos, o que pode ser explicado pelas temáticas das ações (infográfico 2), tendo um aumento da discussão pelo direito à EI no último período analisado e do EF a partir dos anos 2000, pelo questionamento da data corte para ingresso no EF de 9 anos.
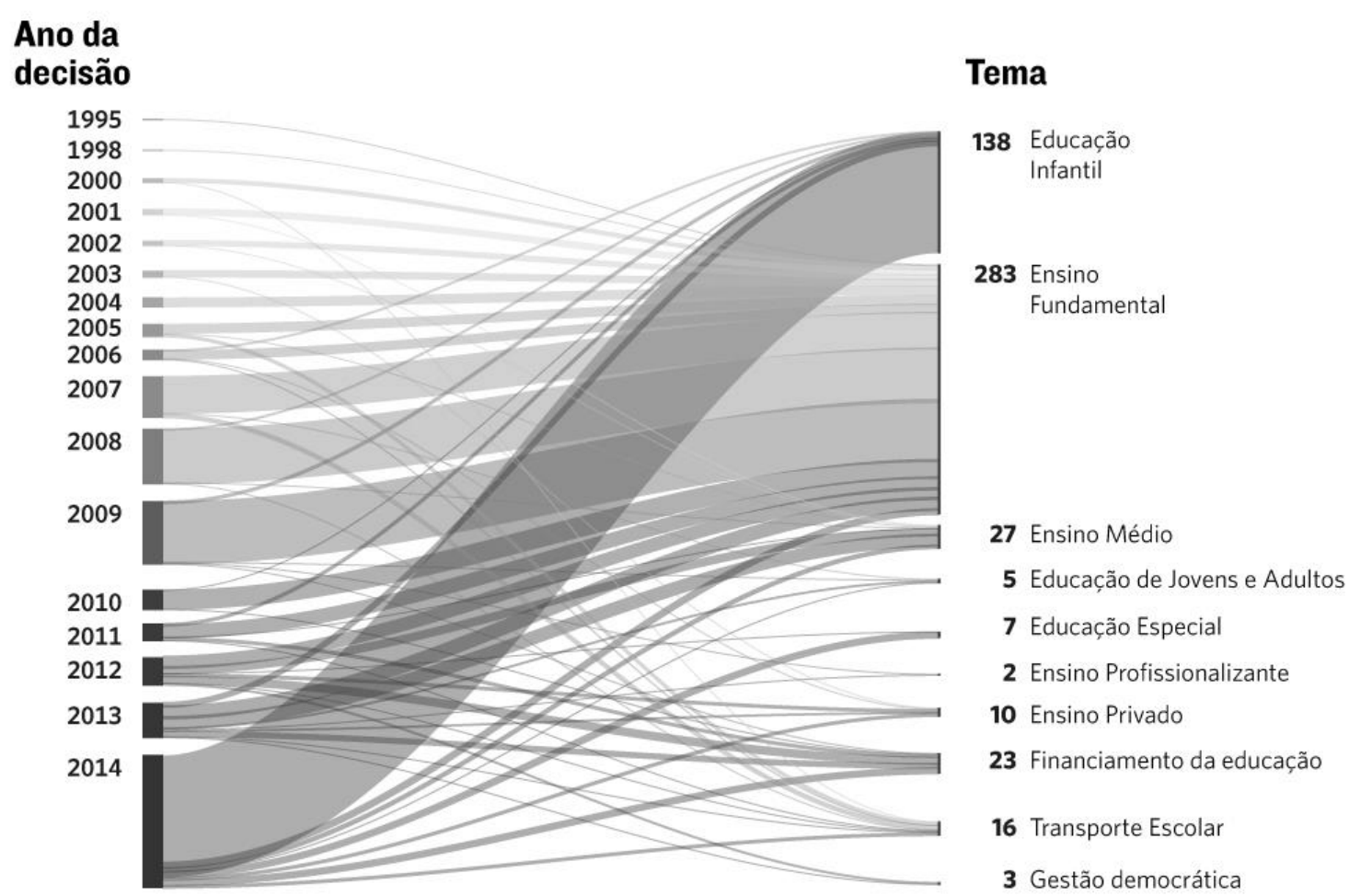

Infográfico 2. Ano da decisão relacionado ao total dos temas Fonte: Banco de dados de decisões organizado para esta pesquisa

Quando se analisa as etapas da educação básica, os questionamentos que enfocam o EF são os mais presentes (283), com 263 decisões sobre a data corte de ingresso nessa etapa. Os demais julgados sobre EF referem-se às ações individuais, concernentes à indenização por danos materiais e morais, medida disciplinar com expulsão de aluno, exigência de matrícula diante de instituição que a negou para alunos com transtorno de déficit de atenção com hiperatividade (TDAH), possibilidade de redução da pena, a política do georreferenciamento no estado do $\mathrm{PR}$, com ordem de matrícula de aluno em escola próxima à residência, mudança de estabelecimento educacional garantindo o transporte, ilegalidade da greve de professores e questionamentos sobre a reprovação.

Das ações de EI, 120 são ações individuais, solicitando a matrícula em creche; 11 são ações coletivas de ampliação do atendimento nessa etapa; uma sobre pedido de matrícula de filho

\begin{tabular}{l|c|c|c|c|c|c|} 
(C) Rev. Educ. Perspec. & Viçosa, $M G$ & v.8 & n.3 & AOP & set./dez. 2017 & eISSN 2178-8359 \\
\hline
\end{tabular}


de servidor em creche criada pela Universidade Estadual de Maringá; seis versando sobre indenização por danos morais e materiais em razão de acidente ocorrido dentro do estabelecimento escolar ou por maus-tratos.

As decisões envolvendo o ensino médio, com um número muito menor que as etapas da educação básica que o precedem, em oito discutem especificamente a reprovação; em cinco as medidas disciplinares com responsabilização do Estado por agressão física e pela forma como o aluno foi tratado pelos profissionais da educação, indenização por danos morais, expulsão de aluna de colégio estadual por estar usando piercing; duas delas dizem respeito à manutenção de matrícula em escola fora do georreferenciamento; em três ações a certificação por problemas em documentação e/ou instituição não credenciada; em outras três tratavam de pedidos de indenização por danos morais, estéticos e materiais para aluno que sofreu queda no interior da escola e ao aluno agredido no interior da instituição.

Ainda sobre ensino médio, foram julgadas duas ações do Sindicato dos Trabalhadores da Educação do PR (APP - Sindicato), uma questionando a redução de carga horária para professores do ensino médio noturno e, em outra, o direito de finalização do programa de formação de professores, com a convocação emergencial de professores. Em outra ação coletiva questionou-se a permissão de funcionamento de uma instituição pública que não apresentava condições adequadas, com alegação de inexistência de documentações de funcionamento e de aprovação do corpo de bombeiros e da vigilância sanitária, exigindo fechamento da instituição com transferência dos estudantes e docentes a outras instituições da rede. Em outras ações individuais, foram abordados o direito de matrícula em turno matutino e o extravio de documento comprobatório de conclusão de ensino médio a distância, por parte da instituição de ensino. A Associação de Preservação da Cultura Cigana questionou a distribuição de obras literárias em escolas estaduais de ensino médio, pedindo a retirada de exemplares de livro que apresentava imagem preconceituosa dos ciganos, bem como pagamento de indenização por danos morais.

Quanto às Comarcas, observa-se maior incidência de casos na capital do Estado (91 decisões), seguida do município de Araucária (90 decisões), Umuarama (34), Cascavel, Maringá (22), da região metropolitana de Curitiba (18), Foz do Iguaçu (15), Engenheiro Beltrão (13), Campina da Lagoa (13) e São José dos Pinhais (12). Esses municípios estão entre os mais populosos do estado e são sedes de Comarcas, o que pode significar maior acesso da população às instituições do Sistema de Justiça. Porém, há outro aspecto que precisa ser melhor analisado para compreender esse processo, e que está relacionado à oferta educacional. Destaca-se que em Araucária, todos os julgados versam sobre EI, com somente uma ação coletiva, sendo as demais individuais. E, em Umuarama, todas têm como alvo o EF, discutindo o corte etário e com ações individuais. Os temas das ações da Comarca de Curitiba e região metropolitana são mais diversos.

\begin{tabular}{l|c|c|c|c|c|c|} 
(C) Rev. Educ. Perspec. & Viçosa, $M G$ & v.8 & n.3 & AOP & set./dez. 2017 & eISSN 2178-8359 \\
\hline
\end{tabular}




\section{Energiñ}

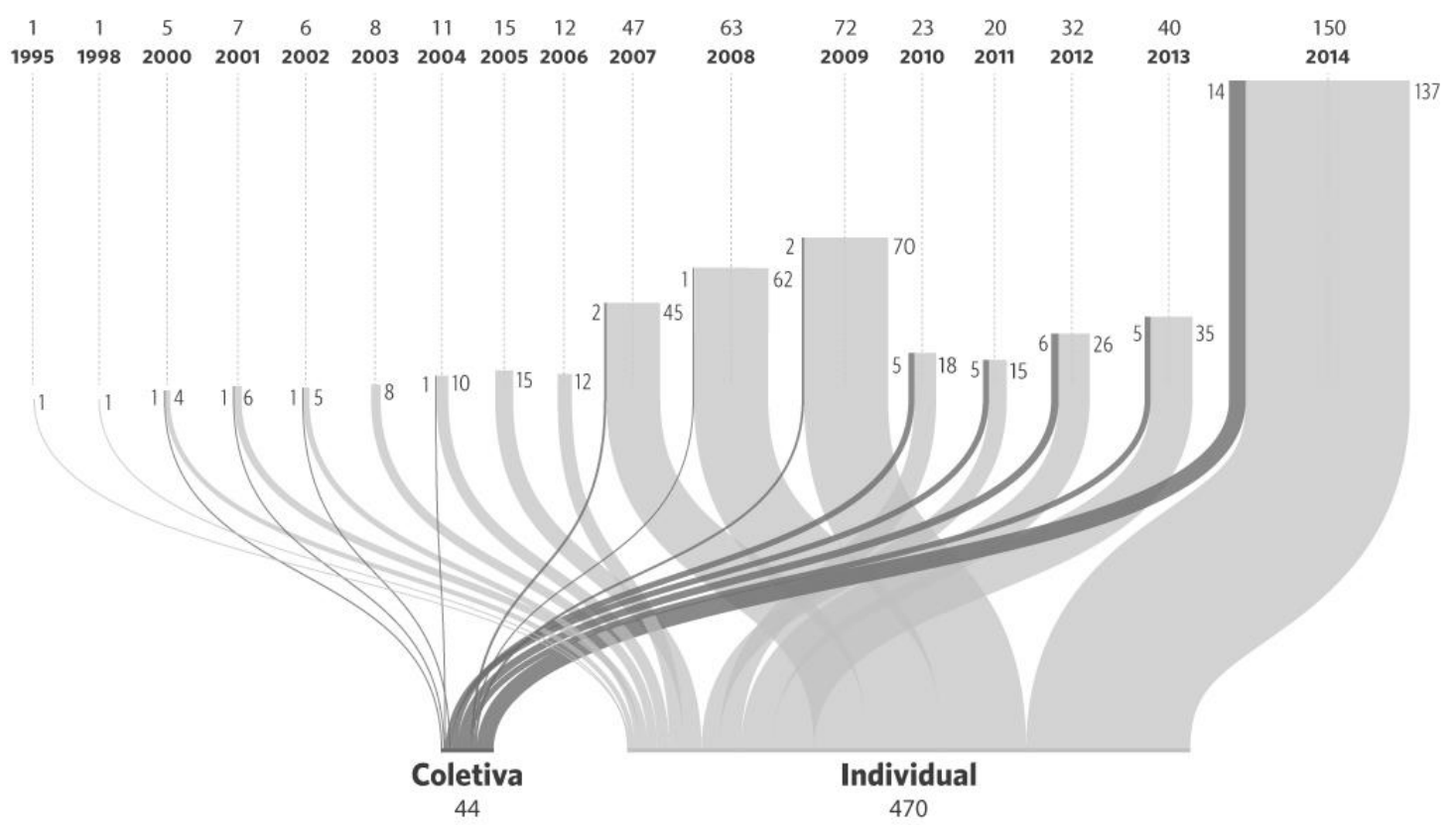

Infográfico 3. Natureza da tutela por ano

Fonte: Banco de dados de decisões organizado para esta pesquisa

A educação é questionada no Judiciário paranaense por sua maioria expressiva de ações individuais, 91,4\% do conjunto analisado. As ações coletivas (44) foram ingressadas, em sua maioria, pelo MP, e versam sobre a ampliação de vagas em EI, com seis Ações Civis Públicas em 2014, o que pode ser reflexo do Projeto Estratégico do MP e sobre o corte etário.

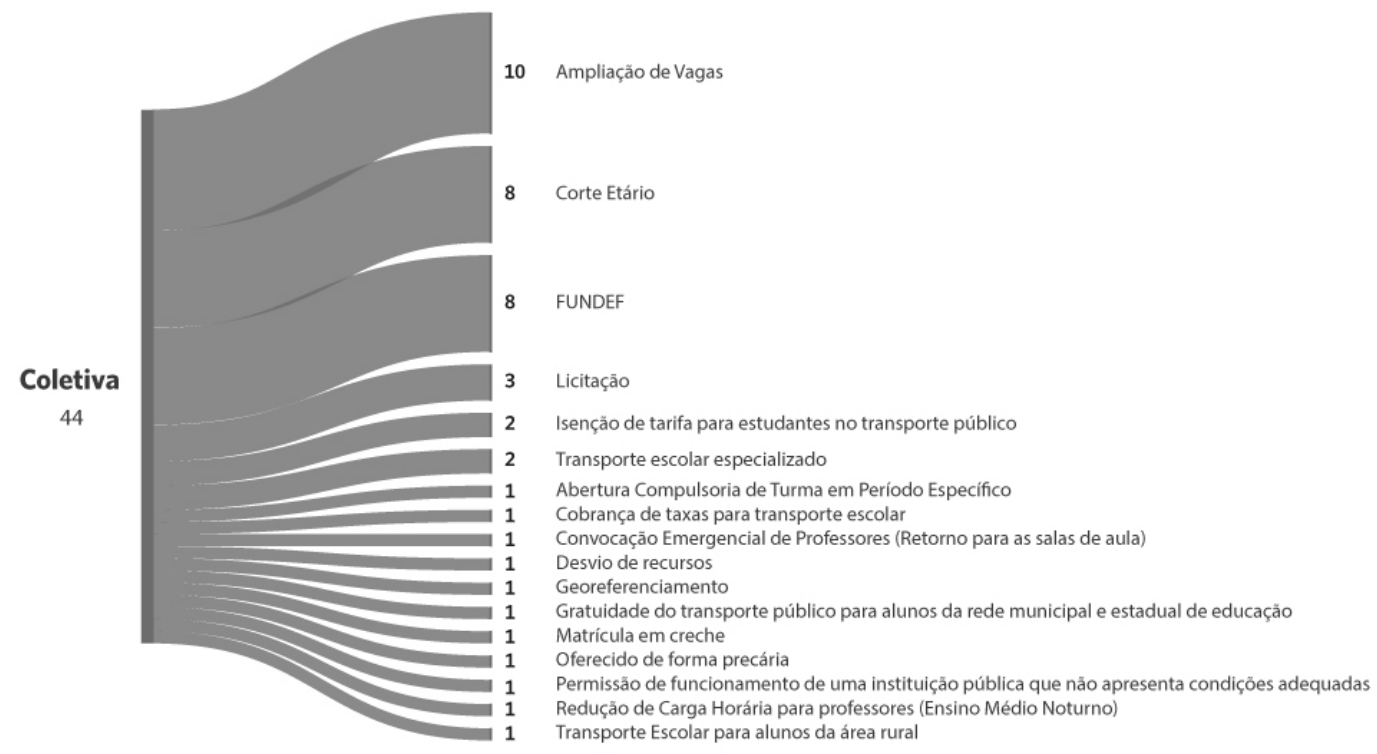

Infográfico 4. Natureza da tutela - Ações coletivas por subtemas Fonte: Banco de dados de decisões organizado para esta pesquisa 
Como a maioria das ações julgadas pelo TJ-PR são individuais, ao analisar o perfil dos ingressantes observa-se, também, que são propostas por particulares, tendo como objeto o ingresso no EF pela data corte de matrícula e a matrícula em EI. O MP figurou como ingressante em 45 decisões, na maioria com ações coletivas, sobre corte etário, ampliação de vagas em EI, transporte escolar e questionamento sobre o financiamento da educação (infográfico 5).

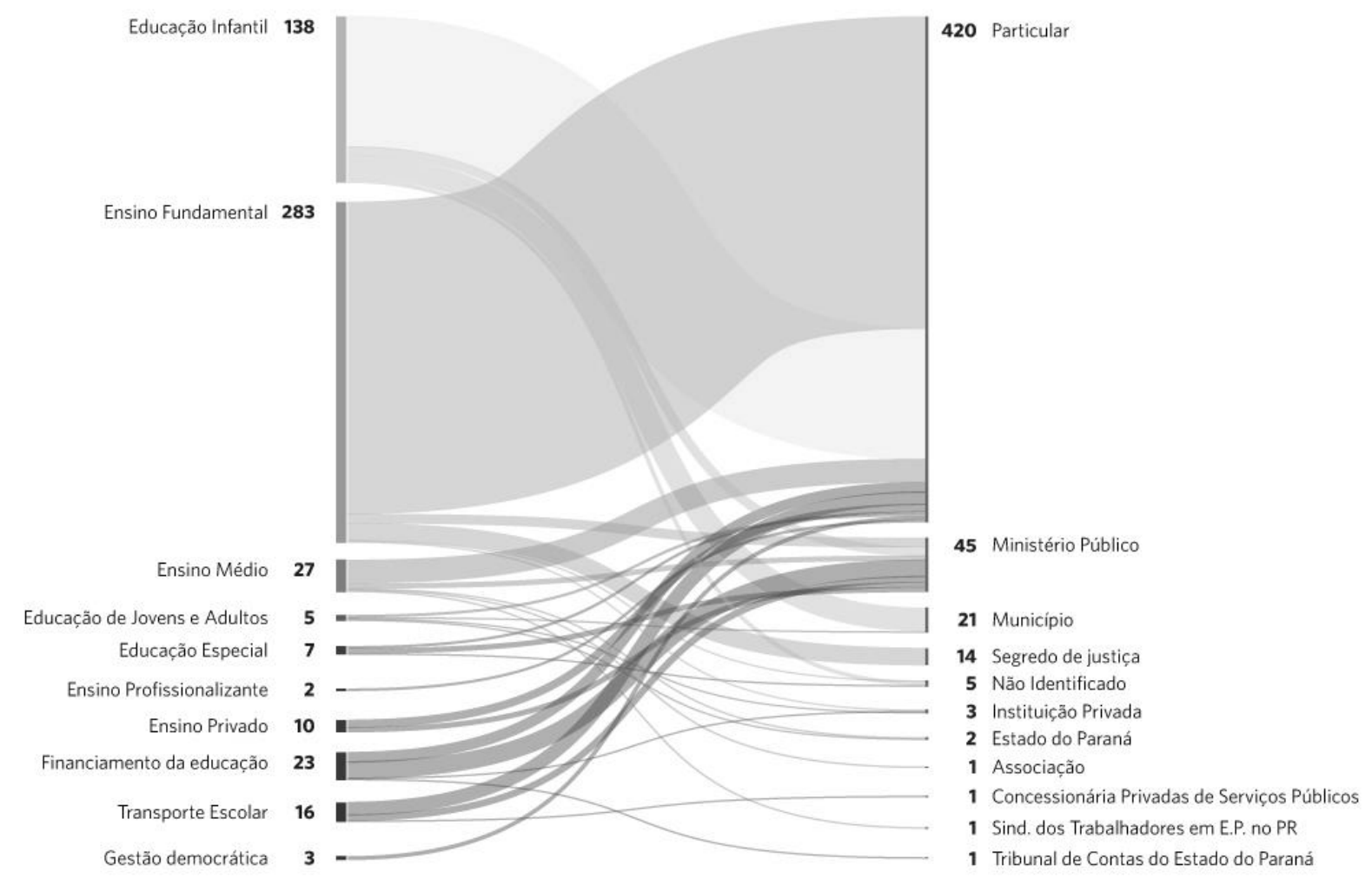

Infográfico 5. Ingressantes por temas

Fonte: Banco de dados de decisões organizado para esta pesquisa

Quanto à natureza das ações julgadas pelo TJ-PR observa-se que a maioria é de mandados de segurança (379), reflexo do alto número de ações individuais que solicitavam o direito à matrícula tanto no EF como na EI. Ação Civil Pública visa a reparação de danos causados ao meio ambiente, ao consumidor, a bens e direitos de valor artístico, estético, histórico, turístico e paisagístico. E, pelo ECA, compete ao MP promovê-la para a proteção dos interesses individuais, difusos e coletivos relativos à infância e à adolescência. Foi utilizado em 43 julgados.

As decisões versando sobre a idade de ingresso no EF foram as de maior incidência no TJ-PR no período analisado nesta pesquisa (263 decisões). Com a promulgação das leis 11.114/05 e 11.274/06 o EF passou a ser obrigatório para as crianças com 6 anos, aumentando um ano nessa etapa do ensino obrigatório e, portanto, totalizando 9 anos de duração. No PR, o CEE, por meio da Deliberação no 03/06, definiu normas para a implantação do EF de 9 anos no seu

\begin{tabular}{l|l|l|l|l|l|l} 
(C) Rev. Educ. Perspec. & Viçosa, $M G$ & v.8 & n.3 & AOP & set./dez. 2017 & eISSN 2178-8359 \\
\hline
\end{tabular}


sistema de ensino, estabelecendo a data de $1^{\circ}$ de março como limite para que a criança completasse 6 anos. No mesmo ano, ocorreram muitas ações ingressadas por famílias e instituições privadas requerendo o direito à matrícula para os que iriam completar 6 anos após o início do ano letivo. Mediante Ação Civil Pública, o MP requereu a matrícula dos educandos que completassem 6 anos até 31 de dezembro. A justiça paranaense declarou-se favorável ao pedido em liminar, determinando a inclusão no $1^{\circ}$ ano do EF de 9 anos de todas as crianças com 6 anos completos ou a completar no decorrer do ano letivo.

Relativo ao tema, o MP, como já destacado, emitiu a nota técnica 01/08 em repúdio à deliberação do CEE e reforçando a necessidade de cumprimento da decisão judicial. Em 2009, a Assembleia Legislativa do PR editou a Lei $\mathrm{n}^{\circ}$ 16.049/09 provendo o direito à matrícula no $1^{\circ}$ ano a crianças que completassem 6 anos até o dia 31 de dezembro do ano em curso.

A maior parte da demanda por ingresso no EF após o início do ano letivo veio de escolas privadas, com maior número de processos entre 2007 a 2009, mas sendo julgadas ações sobre o tema em todo o período analisado. $\mathrm{O}$ argumento da petição inicial mais utilizado foi o da demonstrada capacidade intelectual por meio de laudo psicopedagógico. Os pedidos só foram negados quando as crianças tinham menos de cinco anos, ou não completariam seis anos de idade no ano letivo em que a ação foi ajuizada. Não houve nenhum julgado que considerasse as razões jurídicas e pedagógicas do cabimento do corte de seis anos completos e, portanto, do direito à infância, demonstrando, dessa forma, grande unicidade na jurisprudência paranaense.

O segundo maior número de decisões refere-se à falta de vagas em EI no estado do PR. Em 120 delas requisita-se vaga em creche por meio de mandados de segurança individuais. A jurisprudência do TJ-PR, para esse tipo de ação, está consolidada, mantendo em todas as ações a decisão anterior, ou seja, com negativa do recurso dos municípios. Os argumentos na decisão baseiam-se em: o direito das crianças de zero a seis anos de idade à vaga em creche e/ou pré-escola encontra embasamento legal; que havendo imposição legal ao município de atendimento gratuito em creches ou pré-escolas às crianças de zero a cinco anos de idade (Art. 208, IV, da CF/88 na redação dada pela Emenda Constitucional n ${ }^{\circ}$ 53/2006), não pode o ente federado esquivar-se do seu dever, nem mesmo sob alegação de falta de vagas; direito líquido e certo do impetrante; princípio da reserva do possível não pode ser um obstáculo para a efetivação de direitos sociais e fundamentais; inocorrência de violação aos princípios da separação de poderes; ausência de ingerência no poder discricionário do poder executivo.

Nas ações coletivas, as decisões do TJ-PR, na sua maioria, são para a manutenção da decisão em primeira instância, ou seja, negando o recurso do poder municipal. Nessas ações afirmouse que o direito à EI se configura como direito social básico e necessário ao mínimo

\begin{tabular}{l|c|c|c|c|c|c|} 
(C) Rev. Educ. Perspec. & Viçosa, $M G$ & v.8 & n.3 & AOP & set./dez. 2017 & eISSN 2178-8359 \\
\hline
\end{tabular}


existencial do ser humano, não sendo ofensa ao princípio da divisão dos poderes e que há inexistência de lesão à ordem pública, inaplicabilidade do princípio da reserva do possível. Os precedentes do STJ e do próprio TJ-PR foram também utilizados como argumento para reafirmar que o atendimento em EI pelos municípios é a implementação de política pública determinada constitucionalmente. Todavia, no recurso do Município de Quarto Centenário, de julho de 2009, foi decidido pela impossibilidade jurídica do pedido, com extinção do processo, pois na alegação da relatora "O Poder Judiciário não pode invadir a área de atuação do Poder Executivo, determinando a manutenção dos serviços de creche, porque se assim fora, implicaria em se afastar da sua missão de julgar, para, de forma exorbitante, passar a administrar" (APELAÇÃO CÍVEL, 575934-2, 2009). Essa decisão teve a declaração de um voto vencido, o que demonstra que não é um posicionamento de consenso no TJ-PR.

\section{CONSIDERAÇÕES FINAIS}

Este artigo buscou realizar mapeamento das decisões julgadas pelo TJ-PR, versando sobre educação no período de 1995-2014, e analisar a atuação do MP, por meio do CAOPCAE Área Educação. Os resultados desse mapeamento indicam que a maioria das ações no TJ-PR é ingressada visando uma demanda individual, por meio do mandado de segurança, buscando-se, dessa forma, a solução de um conflito para cada indivíduo e/ou para um grupo determinado, tendo-se um percentual pequeno de ações coletivas, para a defesa dos interesses difusos e coletivos, por meio de Ação Civil Pública, ingressada pelo MP. As ações coletivas envolvem decisões sobre abertura de novas vagas para atendimento das crianças em creche e pré-escola; fornecimento de transporte escolar para os alunos do ensino médio, abertura de vagas de ensino médio no período diurno; legislação do CEE sobre a data para completar seis anos para ingresso no primeiro ano do EF, convênio celebrado entre o estado do PR e município para repasse de verbas para prestação, pelo município, de serviço público de transporte escolar dos alunos residentes na área rural. A análise do conteúdo das decisões coletivas indica como principais elementos nos argumentos das partes envolvidas e dos magistrados: a interferência do Poder Judiciário em atividade de competência do Poder Executivo, considerando o princípio da separação dos poderes; limite à margem de discricionariedade do administrador público; a inviabilidade financeira para o cumprimento do direito questionado.

Destaca-se o número expressivo de ações questionando o ingresso no primeiro ano do EF no estado, tanto por meio de ações individuais como coletivas. Sobre esse tema o Judiciário e o MP foram decisivos para a alteração da política educacional no estado, em oposição ao CEE. Outro tema de destaque refere-se às demandas judiciais, individuais e coletivas, visando a matrícula na EI, vinculada ao baixo percentual de atendimento em muitos municípios paranaenses e, também, produto do planejamento estratégico do MP para essa área, com

\begin{tabular}{l|l|l|l|l|l|l|} 
(C) Rev. Educ. Perspec. & Viçosa, $M G$ & v.8 & n.3 & AOP & set./dez. 2017 & eISSN 2178-8359 \\
\hline
\end{tabular}


ações judiciais de âmbito coletivo e Termos de Ajustamento de Conduta (TACs), o que tem induzido a ampliação do acesso à EI.

Por meio da análise dos dados, tanto da atuação do MP como das ações julgadas pelo TJ-PR, foi possível compreender as possibilidades e os limites da litigação como estratégia para a garantia do direito à educação, proclamada no texto constitucional e, consequentemente, de justiça social para os que têm seu direito negado. Os resultados favoráveis à litigação fortalecem o direito à educação no estado e têm conduzido à busca por novas ações nos Tribunais. Evidencia-se também o papel que o MP vem desempenhando na área educacional no estado, seja por meio do CAOPCAE - Área Educação e da Promotoria de Justiça de Proteção à Educação de Curitiba, como ator político estratégico participando da discussão da pauta educacional, assim como direcionando políticas públicas.

\section{REFERÊNCIAS}

BARROSO, Luís Roberto. O controle de constitucionalidade no direito brasileiro: exposição sistemática da doutrina e análise crítica da jurisprudência. 4 ed. São Paulo: Saraiva, 2009.

BRAGA, Diana Barbosa Gomes. Direito à educação e o Ministério Público do Pará - sua atuação como agente fiscalizador. Dissertação (Mestrado em Educação) - Universidade Federal do Pará, Instituto de Ciências da Educação, Programa de Pós-Graduação em Educação, Belém, 2010.

BORGES, Marina Soares Vital. A atuação do sistema de justiça na efetivação dos direitos fundamentais: um estudo sobre o direito à educação básica, na comarca de Florianópolis/SC, no período de 2000 a 2005. Dissertação (mestrado) - Universidade Federal de Santa Catarina, Centro de Ciências Jurídicas. Programa de Pós-Graduação em Direito, 2007.

CAJUELLA, Fayola Sant'Anna. $O$ acesso à justiça e o direito à educação infantil: um estudo sobre a atuação da Defensoria Pública do Estado de São Paulo. Dissertação (mestrado) - Escola de Direito de São Paulo da Fundação Getúlio Vargas, 2016.

CURY, Carlos Roberto Jamil.; AMARAL, Claúdia Tavares. O direito à educação básica: análise inicial dos julgamentos do Tribunal de Justiça de Minas Gerais. IV Congresso IberoAmericano de Política e Administração da Educação VII Luso-Brasileiro. Porto, Portugal, 2014.

DAMASCO, Denise Gisele de Britto. O direito à educação: a atuação das promotorias de justiça e de defesa da educação do Ministério Público do Distrito Federal e Territórios, entre 2001 e 2007. Universidade de Brasília, 2008. 
DUARTE, Clarice Seixas. Reflexões sobre a Justiciabilidade do Direito à Educação no Brasil In: HADDAD, Sérgio; GRACIANO, Mariângela (Org.) A educação entre os direitos humanos. Campinas, SP: Autores Associados; São Paulo, SP: Ação Educativa, 2006.

DUARTE, Clarice Seixas. A educação como um direito fundamental de natureza social. Revista Educação e Sociedade, Campinas, v. 28, n. 100 - Especial, p. 691-713, out. 2007.

GOTTLIEB, Gabriele. Judicialização dos direitos sociais: as ações coletivas que demandam políticas públicas no foro Central de Porto Alegre. Porto Alegre, 123 p. Dissertação (Mestrado em Ciência Política) - Universidade Federal do Rio Grande do Sul, Porto Alegre, 2011.

MACHADO, Edson. A Jurisprudência educacional do Supremo Tribunal Federal, na vigência da Constituição de 1988 da República Federativa do Brasil. 2003. 122 p. Dissertação (Mestrado) - Faculdade de Educação, Universidade de São Paulo, São Paulo, 2003.

MARINHO, Carolina Martins. Justiciabilidade dos direitos sociais: análise de julgados do direito à educação sob o enfoque da capacidade institucional. 2009. 120 p. Dissertação (Mestrado em Direito). Universidade de São Paulo, São Paulo, 2009.

MARTINES JUNIOR, Eduardo. Educação, Cidadania e Ministério Público: o artigo 205 da Constituição e sua abrangência. 2006. 446 p. Tese (Doutorado em Direito) - Pontifícia Universidade Católica de São Paulo, São Paulo, 2006.

OLIVEIRA, Romualdo Portela. Educação e Cidadania: o Direito à educação na Constituição de 1988 da República Federativa do Brasil. 1995. 179 p. Tese (Doutorado) Faculdade de Educação, Universidade de São Paulo, São Paulo, 1995.

OLIVEIRA, Vanessa Elias de. As fases do processo de políticas públicas. In: MARCHETTI, Vitor (Org.). Políticas públicas em debate. São Bernardo do Campo, SP: MP Editora, 2013.

PARANÁ, Ministério Público. Ato no 27, de 9 de abril de 2002. Criação, extinção e alteração dos Centros de Apoio Operacional, 2002.

PARANÁ, Ministério Público. Centro de Apoio Operacional às Promotorias da Educação, Promotoria de Justiça de Proteção à Educação - Foro Central. Nota Técnica 01/2008. Paraná. Disponível em:

<www.educacao.mppr.mp.br/arquivos/File/dwnld/educacao_basica/ensino_fundament al/nota_tecnica_001_2008_caopeduc/nota_tecnica_001_2008_caopeduc.doc $>$. Acesso em: 30 abr. 2013.

RIOS-FIGUEROA, Julio; TAYLOR, Matthew M. Institucional Determinats of the Judicialisation of policy in Brazil and México. Journal of Latin American Studies. Cambridge University Press, United Kingdom, 38, p. 739-766, 2006. 
RIZZI, Ester; XIMENES, Salomão. Litigância estratégica para a promoção de políticas públicas: as ações em defesa do direito à educação infantil em São Paulo. In: Justiça e direitos humanos: experiências de assessoria jurídica popular. Curitiba: Terra de Direitos, 2010.

SCAFF, Elisângela Alves da Silva; PINTO, Isabela Rahal de Rezende. O Supremo Tribunal Federal e a garantia do direito à educação. Revista Brasileira de Educação, v. 21, p. 431454, 2016.

SILVEIRA, Adriana Dragone. Direito à Educação e o MP: Uma análise da atuação de duas Promotorias de Justiça da Infância e Juventude do interior paulista. Dissertação (Mestrado) Faculdade de Educação da universidade de São Paulo, SP, 2006.

SILVEIRA, Adriana Dragone. Judicialização da educação para a efetivação do direito à educação básica. Jornal de políticas educacionais, n. 9, p. 30-40, jan/jun. 2011.

SILVEIRA, Adriana Dragone. Atuação do Tribunal de Justiça de São Paulo com relação ao direito de crianças e adolescentes à educação. Revista Brasileira de Educação (Impresso), v. 17, p. 353-497, 2012.

SILVEIRA, Adriana Dragone. A busca pela efetividade do direito à educação: análise da atuação de uma Promotoria de Justiça da Infância e Juventude do interior paulista. Educar em Revista (Impresso), n. 2, p. 233-250, 2010.

SOUSA SANTOS, Boaventura et. al. Os tribunais nas sociedades contemporâneas: o caso português. Porto: Edições Afrontamento, 1996.

SOUSA SANTOS, Boaventura. Para uma revolução democrática da justiça. São Paulo: Cortez, 2007.

TAYLOR, Matthew M. O Judiciário e as políticas públicas no Brasil. Dados - Revista de Ciências Sociais, Rio de Janeiro, v. 50, n. 2, p. 229-257, 2007.

TATE, Neal.; VALLINDER; Torbjorn. (Ed.). The Global Expansion of Judicial Power. New York: New York University Press, 1995.

\section{NOTAS}

\footnotetext{
${ }^{1}$ A política pública é compreendida em suas diferentes fases com a construção da agenda, formulação da política, processo decisório, implementação e avaliação (OLIVEIRA, 2013).

${ }^{2}$ A Comissão Permanente de Educação (COPEDUC) tem como meta a criação de um banco de dados nacional com peças jurídicas sobre o tema produzidas em todos os Estados do país. Também estão entre os objetivos principais da Comissão o fomento à criação de Centros de Apoio e Promotorias especializadas na área. Estimular, fiscalizar e apoiar o funcionamento dos Conselhos de Controle Social (Conselho de Alimentação e Conselho do FUNDEB) também é uma das metas da COPEDUC. Disponível em: <http://www.cnpg.org.br/index.php/gndh/3936-metas>. Acesso em: 18 fev. 2015.
}

\begin{tabular}{l|c|c|c|c|c|c} 
(C) Rev. Educ. Perspec. & Viçosa, $M G$ & v.8 & n.3 & AOP & set./dez. 2017 & eISSN 2178-8359
\end{tabular}


${ }^{3}$ Disponível em: 〈http://www.crianca.mppr.mp.br/arquivos/File/cnpg/gndh_24_set_2013_copia.pdf〉. Acesso em: 16 jul. 2014.

${ }^{4}$ Mais informações em: <http://www.educacao.mppr.mp.br/>. Acesso em: 21 ago. 2017.

${ }^{5}$ Fonte: MEC - Portal Planejando a próxima década.

${ }^{6}$ As decisões envolvendo segredo de justiça não são disponibilizadas para consulta.

7 As decisões judiciais foram coletadas no portal eletrônico do Tribunal de Justiça do Paraná, <http://portal.tjpr.jus.br/jurisprudencia/>, inserindo no campo "pesquisa detalhada" as etapas e modalidades da educação básica: "educação infantil", "creche", "pré-escola"; "ensino fundamental", "ensino médio", "educação especial", "educação de jovens e adultos", contando com a participação dos integrantes da pesquisa. O procedimento de coleta e organização dos dados contou com a colaboração, em diferentes fases, dos integrantes da pesquisa: Hellen Martins Quadros; Katherine Finn Zander, Jair dos Anjos Silva; Soeli Terezinha Pereira; Marina Feldman; Barbara Hanuer e Izabella de Macedo.

${ }^{8}$ Do conjunto das decisões também foram desconsideradas as decisões envolvendo questões trabalhistas individuais dos profissionais da educação, como: desclassificação em concurso público, acúmulo de cargo de professores, não registro de diplomas (Programa Especial de Capacitação para a docência de EF e educação infantil) decorrentes da Faculdade Vizinhança Vale do Iguaçu (VIZIVALI).

\section{Sobre a Autora}

Adriana Dragone Silveira: Professora do Departamento de Planejamento e Administração Escolar e do Programa de Pós-graduação em Educação. E-mail:

adrianadragone@yahoo.com.br 